\title{
TODO ESPAÇO É POLÍTICO: ATIVISMO DE MULHERES NAS REDES SOCIAIS
}

\author{
EVERY SPACE IS POLITICAL: WOMEN'S ACTIVISM IN SOCIAL MEDIA
}

\section{TODO EL ESPACIO ES POLÍTICO: EL ACTIVISMO DE LAS MUJERES EN REDES SOCIALES}

Desirée Pires ${ }^{1}$

Amanda Motta ${ }^{2}$

\section{RESUMO}

Na última década houve uma maior articulação dos movimentos sociais utilizando como recurso de propagação de suas pautas as mídias e, principalmente, as redes sociais. O movimento feminista também vem se apropriando desses espaços, demonstrando que é capaz de interagir e de alcançar um público que até mesmo não era atingido em momentos anteriores. No Brasil, manifestações como a Marcha das Vadias (2015) e o \#EleNão (2018) demonstram que o movimento feminista não permanece, apenas, nas redes sociais, mas que possibilita uma articulação e organização que resultam em manifestações e protestos nas ruas, trazendo pautas que vão para além do ser mulher na sociedade brasileira. Sendo assim, a proposta deste artigo, o qual compõe uma pesquisa de mestrado desenvolvida no Programa de pós-graduação em Educação/PPGEDU da Universidade Federal do Rio Grande/FURG, é realizar um levantamento bibliográfico sobre ativismo de mulheres nas redes sociais, o ciberfeminismo. Buscamos aqui responder a uma pergunta central: o que foi produzido no Brasil sobre o ativismo de mulheres nas redes sociais na última década?

Palavras-chave: movimento feminista; ativismo; redes sociais; educação.

\section{RESUME}

Submetido em: 28/03/2020 - Aceito em: 21/06/2020 - Publicado em: 18/08/2020.

1 Mestranda no Programa de Pós-Graduação em Educação/PPGEDU da Universidade Federal do Rio Grande/FURG. Graduada em História Licenciatura pela mesma universidade. Contato: desiree.pires@hotmail.com

2 Professora do Programa de Pós-Graduação em Educação da Universidade Federal do Rio Grande do Sul/FURG e docente do Departamento de Educação da mesma instituição. Doutora pelo programa de PósGraduação em Educação da Universidade do Vale do Rio dos Sinos/UNISINOS. Contato: motta.amanda@gmailcom 


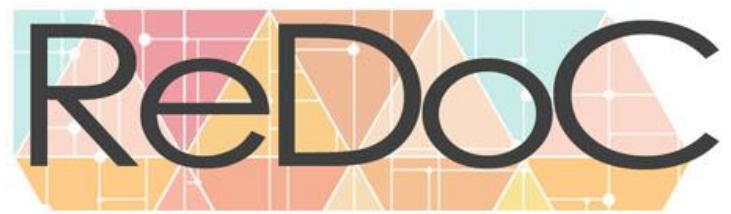

Revista Docência e Cibercultura

In the past decade there have been a greater articulation of the social movements using as a propaganda research the mídias and, mainly, the social media. The feminist movement also appropriates of theses spaces, evidencing the capability of reaching a type of public that was not reached in early moments. In Brazil manifestations such as Marcha das Vadias (2015) and \#EleNão (2018) demonstrate that the feminist movement is not presente, solely, in the internet. Also, the movement makes it possible the interaction and organization of it's participants, in which results in manifestaions and protests on streets, of which the demands are not restricted only to women's issues in brazilian society. Therefore, the proposal of this text, which composes a researche of master's degree developed by Programa de pós-graduação em Educação/PPGEDU in the Universidade Federal do Rio Grande/FURG, is to accomplish a bibliographic survey about the women's activism in social media, known as cyberfeminism. We intend here to answer a central question? What have been produced in Brazil about women's activism in social media for the past decade?

Key-words: feminist movement; activism; social media; education.

\section{RESUMEN}

En la última década hubo una mayor articulación de los movimientos sociales utilizando como recurso para la propagación de sus directrices a los medios y, principalmente, a las redes sociales. El movimiento feminista también se ha apropiado de estos espacios, demostrando que es capaz de interactuar y llegar a una audiencia que ni siquiera se alcanzó en momentos anteriores. En Brasil, manifestaciones como March of Sluts (2015) y \# EleNo (2018) demuestran que el movimiento feminista no solo permanece en las redes sociales, sino que permite la articulación y organización que resultan en manifestaciones y protestas en las calles, trayendo pautas que van más allá de ser mujer en la sociedad brasileña. Por lo tanto, la propuesta de este artículo, que compone una investigación de maestría desarrollada en el Programa de post-graduación en Educación / PPGEDU de la Universidad Federal de Río Grande / FURG, es realizar una búsqueda bibliográfica sobre el activismo de las mujeres en las redes sociales, el ciberfeminismo. Buscamos aquí responder una pregunta central: ¿qué se ha producido em Brasil sobre el activismo de las mujeres en las redes sociales en la última década?

Palabras clave: movimiento feminista; activismo; redes sociales; educación

\section{INTRODUÇÃO}

Nunca se esqueça que basta uma crise política, econômica ou religiosa para que os direitos das mulheres sejam questionados. Esses direitos não são permanentes. Você terá que manter-se vigilante durante toda a sua vida.

(Simone de Beauvoir, 2009)

O texto que se apresenta faz parte de um recorte que compõe uma pesquisa de mestrado que está sendo desenvolvida no Programa de pós-graduação em Educação/PPGEDU da Universidade Federal do Rio Grande/FURG. Nos últimos anos percebemos uma efervescência dos movimentos sociais no Brasil, que percebem as redes sociais como uma importante ferramenta de articulação. O ciberativismo vem se apresentando 


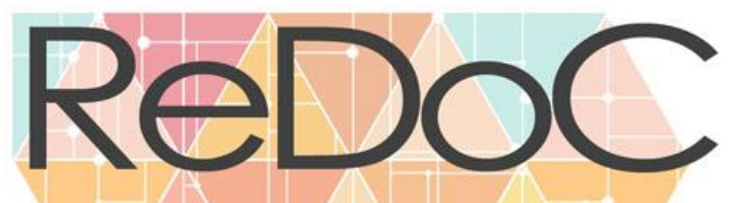

\section{Revista Docência e Cibercultura}

como uma estratégia de ativismo dos mais diversos movimentos sociais, tendo em vista o poder de alcance que a informação produz através da internet e, mais especificamente, por meio das redes sociais.

O movimento feminista, por sua vez, também se apropria desses espaços, fato que culminou inclusive nas manifestações de 2018, as quais originaram o movimento \#EleNão ou hashtag Ele Não. Esse movimento que foi originalmente organizado por mulheres do país todo por meio de um grupo na rede social facebook, intitulado "Mulheres Unidas Contra Bolsonaro", levou centenas de pessoas às ruas e tinha por objetivo impedir a candidatura do então presidente eleito, Jair Bolsonaro. O movimento foi decisivo para levar as eleições para o segundo turno e demonstrar o quanto a internet e, principalmente, as redes sociais têm um grande poder de mobilização. Além disso, o grupo se mantém ativo discutindo diversas problemáticas de gênero, principalmente sobre os retrocessos sobre os direitos de mulheres e das minorias que o atual governo tem causado.

Dessa maneira, o ciberfeminismo, como vem ficando conhecido o movimento, se apresenta enquanto uma estratégia de ativismo feminista, que se utiliza da velocidade de informações que a internet dissemina para informar e conscientizar cada vez mais as mulheres de sua condição de opressão.

Para compreender melhor sobre o ativismo de mulheres nas redes sociais, foi realizado um minucioso estado da arte $^{3}$ - um levantamento bibliográfico sobre essa produção. Buscamos nesse momento responder a uma pergunta: o que foi produzido no Brasil sobre o tema da pesquisa em andamento na última década?

\footnotetext{
${ }^{3}$ Estado de arte é uma expressão usada pelo meio acadêmico que busca fazer um levantamento de pesquisas que foram realizadas sobre o tema a ser pesquisado, geralmente definidas por um recorte de tempo definido pelo pesquisador.
} 




Revista Docência e Cibercultura

\section{ESTADO DA ARTE}

REIS, Carolina. O novo feminismo. Ilustração Mário Henriques

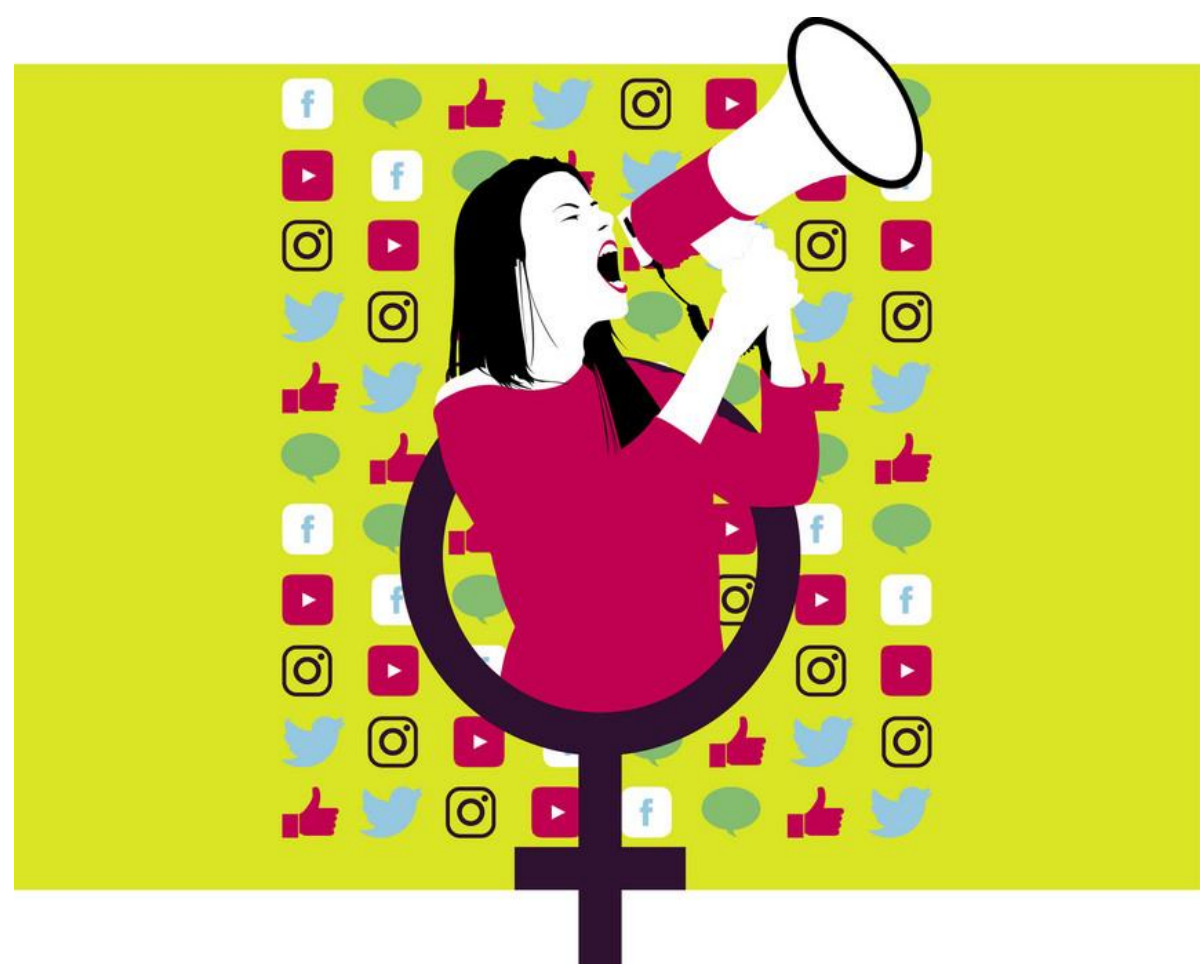

Fonte: https://expresso.pt/sociedade/2016-09-25-O-novo-feminismo

As pesquisas realizadas sobre relações de gênero e movimento feminista no Brasil já constituem uma trajetória bem consolidada no país, perpassando principalmente as áreas de educação, antropologia, história e sociologia. Essas pesquisas ganharam significativo espaço no meio acadêmico principalmente a partir da década de 1980, com o período de redemocratização brasileiro, onde as mulheres tiveram alguns de seus direitos assegurados por meio da Constituição Brasileira de 1988.

No entanto, na última década vemos emergir um outro momento do movimento, atingindo mulheres que até então não eram alcançadas e uma significativa expansão de ideias e conceitos. Pode-se dizer até mesmo que há uma significativa "popularização" do 


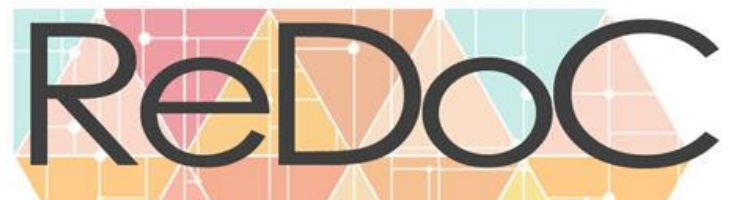

\section{Revista Docência e Cibercultura}

movimento feminista na última década e isto se dá principalmente pelo fenômeno das redes sociais. A popularização do acesso à internet e das redes sociais facilitam a cada ano que passa a comunicação entre os indivíduos, o acesso à informação e a troca de ideias/saberes pelos mais diversos grupos sociais. Essas transformações acabaram refletindo na organização dos movimentos sociais que passaram a perceber esses espaços não simplesmente como espaços de propagação de informação, mas como um novo tipo de organização política, a qual oportuniza uma democracia mais conectada, ativa e transparente. (BOGADO, 2018)

No desenvolvimento do estado da arte sobre as pesquisas realizadas no Brasil com essa temática, definiu-se um recorte de 2009 a 2019. A plataforma utilizada para essa busca foi o banco de dissertações e teses da CAPES, o portal de periódicos da mesma plataforma e a biblioteca digital de dissertações e teses da FURG, universidade em que vem se desenvolvendo a pesquisa. As palavras-chave para a realização desse levantamento foram "ativismo digital", "feminismo" "ciberfeminismo". A tabela abaixo apresenta esse levantamento:

\begin{tabular}{|l|l|}
\hline Palavras-chave & $\begin{array}{l}\text { "Ativismo digital", "Feminismo" e } \\
\text { "Ciberfeminismo" }\end{array}$ \\
\hline Plataformas de busca & $\begin{array}{l}\text { - Banco de dissertações e teses da CAPES } \\
\text { - Portal de periódicos da CAPES } \\
\text { - Biblioteca Digital de Dissertações e } \\
\text { Teses da FURG. }\end{array}$ \\
\hline Idiomas & Espanhol e português \\
\hline Período & $2009-2019$ \\
\hline Resultados & 15 dissertações. 4 teses de doutorado. \\
& Sendo dessas escolhidas 12 para análise. \\
\hline
\end{tabular}

Dentre os textos encontradas envolvendo o tema pesquisado entre dissertações e teses, foram escolhidas para análise as pesquisas que perpassam as diferentes áreas sociais e humanas, sendo estas: comunicação (7), ciência política e social (2), linguagens (1), estudos interdisciplinares de gênero (1) e educação (1).

No que se refere a área da comunicação, a dissertação de Marina Gazire Lemos, intitulada "Ciberfeminismo: novos discursos do feminino em redes eletrônicas", de 2009, tem 
por entendimento de que ciberfeminismo significa “(...) uma prática feminista em rede, que tem por intuito, tanto politicamente, quanto esteticamente, a construção de novas ordens e desmontagem de velhos mitos da sociedade através do uso da tecnologia. (LEMOS, 2009, p. 9) A partir dessa perspectiva, a autora busca analisar as origens do ciberfeminismo, traçando uma trajetória do movimento feminista, a fim de compreender como se constroem esses novos discursos interpelados pelas redes. Dessa maneira, é atribuído o surgimento dessa estratégia de ativismo a um período anterior ao world wibe web (WWW), o qual é o sistema de documentos dispostos na internet que permite o acesso à informação relacionados a hipertextos, ou seja, uma forma de reunir os documentos da internet em forma de acesso por meio de links, semelhante a maneira que acessamos atualmente o conteúdo na internet. Anterior a este momento, o software BBS (bullet bord system) permitia que um computador se conectasse ao outro com o intuito de transferir arquivos, sendo comumente utilizados por empresas na década 1970; também eram utilizados com as intranets universitárias, que eram redes de computador privadas apenas de acesso das universidades, usados em meios corporativos até hoje. Outra possível origem para o ciberfeminismo estaria em Manifesto Ciborgue: ciência, tecnologia e feminismo-socialista no final do século XX, de 1984, escrito pela bióloga Donna Haraway, onde a autora propõe um rompimento com o marxismo, o feminismo radical e outros movimentos sociais que, segundo a autora, não conseguiram fazer a intersecção com as categorias de raça, classe e gênero.

Utilizando como aporte teórico a teoria dos estudos culturais de Stuart Hall, a autora aponta para uma possível crise dos movimentos sociais, no caso em específico do movimento feminista. Ainda se apoiando em Haraway, o objetivo da autora é tentar fazer uma relação diacrônica entre o movimento feminista e o ciberfeminismo, traçando as modificações sofridas as modificações sofridas pelo movimento e que culminam no ciberfeminismo como uma estratégia/tática de luta. Uma perspectiva evolutiva e de viés cronológico.

Seguindo uma análise linear do movimento, a autora Ana Flora Schlindwein em sua dissertação "Dos periódicos oitocentistas ao ciberfeminismo: a circulação das reivindicações feministas no Brasil”, publicado em 2012, define o ciberfeminismo como “(...) um movimento 


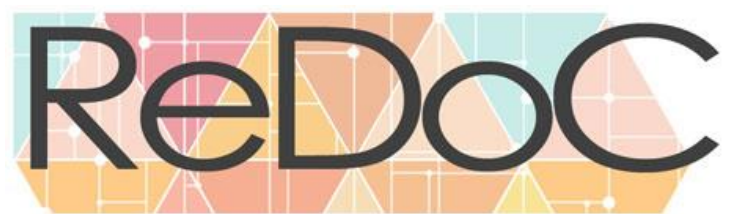

\section{Revista Docência e Cibercultura}

multifacetado - portanto, ciberfeminismo(s) - que atua tanto no campo teórico, em intervenções de natureza mais prática, quanto em atividades teórico-práticas, tendo pelo menos um ponto de sustentação" (SCHLINDWEIN, 2012, p. 83)

Dessa maneira, a autora conta a trajetória histórica das ondas feministas dando um enfoque maior para a terceira onda, evidenciada pelas teorias de Judith Butler e Donna Haraway. A autora compara as reivindicações dos diversos momentos do movimento com as estratégias de utilização das mídias para a popularização das pautas. Para isso, é compreendido que os "zines" (espécie de panfleto feito à mão), por exemplo, são utilizados pelos novos movimentos feministas e que, por meio da divulgação do mesmo pela internet, tem um alcance ainda maior entre os grupos que teriam dificuldade de acesso ao material.

Aprofundando a análise, a pesquisadora Maigret (2010) aborda que existe uma constância sobre dois posicionamentos opostos sobre a tecnologia: tecnofóbico, que vê na tecnologia uma forma de controle de massas; tecnofílico, que vê a tecnologia como uma grande aldeia global; e o tecnicista, que percebe na tecnologia a solução dos maiores problemas sociais. Quando a autora fala em tecnologia não está se referindo apenas no período da inserção das tecnologias da informação, mas se refere também aos periódicos e a imprensa do final do século XIX como um recurso tecnológico. Portanto, a autora trata de que os movimentos sociais, incluindo o feminismo, sempre se apropriaram das mais diversas formas de tecnologia de acordo com o seu tempo, sendo o ciberfeminismo apenas o resultado dessa trajetória.

Seguindo esta perspectiva, a autora Ana Paula Pereira Coelho em sua dissertação intitulada "Do sujeito ao ciborgue: ciberfeminismo e teoria feminista para o século XXI Narrativas de ativismo feminista em rede no Twitter", de 2018, também aborda o ativismo feminista na internet como uma evolução do movimento social, se embasando teoricamente no pensamento da teórica Donna Haraway e defendendo a busca por um feminismo menos, em suas palavras, “tecnofóbico". Dessa maneira, busca compreender os pontos do feminismo e os do próprio ciberfeminismo, relacionando mulheres e máquinas como uma simbiose. Para 
isso, propõe-se a analisar as movimentações e ações feministas da rede social Twitter e como as mesmas se apropriam do meio para promover ideais de equidade e liberdade.

Seguindo também como metodologia de trabalho o estudo de caso, a autora Joice Adriana Enzeler, em sua dissertação "Ciberfeminismo e Saúde: uma análise do caso da aprovação e implementação da Lei das Doulas (7314/2016) ", de 2017, buscou apresentar como o ciberativismo pode propiciar uma discussão dos mais diversos problemas que permeiam a sociedade, assim como interferir em micropolíticas, como aprovações de leis e implementação de políticas públicas. Nesse sentido, ela trabalha as disputas entre narrativas produzidas por mulheres dentro ciberespaço, mais especificamente sobre estratégias de articulação para o avanço dos direitos da saúde da mulher. A partir disso, propõe-se a analisar como movimento das doulas no Rio de Janeiro influenciou a criação da "Lei das Doulas", sendo as discussões iniciais sobre o tema, tecidas na internet.

Definindo militância como “(...) lutar por determinadas causas, reivindicar direitos sociais como educação, trabalho, moradia etc." (ENZLER, 2017, p.17), a autora a partir das concepções do autor Pierre Levy (2010) preocupa-se em definir a "militância na internet", como uma estratégia profícua de ativismo, pois não importa exatamente o espaço onde essas ações aconteçam, mas sim, que elas alcancem as pessoas de alguma maneira. Autores como Lévy (2010) e Castells (2013) são muito utilizados pela autora para se referir a importância das interações que acontecem mediadas pelo uso da internet, onde ela ressalta inúmeras vezes que o virtual não anula o real, mas serve de complemento para essas interações.

Apesar de trabalhar com esses autores os quais possuem uma visão muito mais positiva do que negativa sobre a cibercultura ${ }^{4}$ a autora salienta várias vezes que a internet não é um espaço apenas de aproximação de ideias e de opiniões, mas sim de constantes disputas por narrativas. Para isso, a autora cita vários casos de abuso de poder político que ocorreram entre 2015 e 2017 e que feriam os direitos das mulheres, como o projeto de lei do, então presidente da câmara dos deputados, Eduardo Cunha que proibia o uso de pílula do dia seguinte ou do

\footnotetext{
${ }^{4}$ De acordo com Levi (1999), a cibercultura significa o conjunto de técnicas, práticas, atitudes e modos de pensamento que acontecem no espaço virtual.
} 
direito ao aborto em caso de estupro. ${ }^{5}$ A autora também cita a candidatura de Jair Bolsonaro, com um grande número de votos no RJ, representando a onda conservadora que se abateria sobre o Brasil nos anos seguintes.

A autora destaca em sua pesquisa que a maioria das mulheres que encabeçaram o movimento das doulas na internet não se reconhecem enquanto ciberfeministas. Esse ponto demonstra o quanto o ativismo feminista que acontece no Brasil tem características próprias e se distancia dos respectivos lugares de origem, como o movimento feminista estadunidense e europeu. Nesse sentido, ela acredita a partir de suas pesquisas que dentro de alguns anos o ciberativismo representaria um movimento relevante e estratégico para os diversos movimentos sociais.

Demonstrando que o ativismo feminista que acontece nas redes sociais possui suas próprias particularidades na América Latina, a dissertação de Marta Florencia Goldsman, intitulada "\#LibertadParaBelen: twitter y el debate sobre el aborto en la Argentina", de 2018, apresenta outras perspectivas do tema. O trabalho busca abordar uma onda de protestos que ocorreram em 2016 nas redes sociais na Argentina, sendo um dos primeiros protestos massivos contra a criminalização do aborto que aconteceram na internet. A onda de manifestações iniciou-se depois que uma jovem foi presa por dois anos por ter realizado um aborto. Dessa maneira, a autora separou mais de 12.000 tweets a partir da \#LibertadParaBelen.

Um ponto muito relevante é que a autora traça alguns aspectos pessoais que a fizeram procurar por essa pesquisa, tendo em vista seu trabalho na Guatemala, seu país de origem, onde buscava oportunizando a voz das mulheres indígenas pelo de seu trabalho na comunicação, demonstrando uma perspectiva mais humana e íntima de sua realidade.

A partir de uma abordagem linear do tema a autora vai traçando a trajetória histórica de luta das mulheres argentinas em relação ao aborto, os estudos sobre redes sociais, ciberativismos e uma revisão histórica sobre o ciberfeminismo, que inclui alguns

\footnotetext{
${ }^{5}$ Disponível em: < http://g1.globo.com/politica/noticia/2015/10/ccj-da-camara-aprova-lei-que-proibe-venda-dapilula-do-dia-seguinte.html>
} 
apontamentos dessa prática feminista na américa latina e como vem se desenvolvendo na última década.

Dando sequência as pesquisas envolvendo estudos de caso, a dissertação de Luciana Hage de Castro, intitulada "Gênero e o impeachment de Dilma Roussef: uma análise de páginas de facebook feministas e de mulheres ativistas na Amazônia", também de 2018, buscou compreender de que maneira a relação gênero-impeachment estava sendo trabalhada pelas ativistas feministas, sendo analisadas quatro comunidades feministas no facebook localizadas nas cidades de Imperatriz (MA), Rio Branco (ACRE) e Manaus (AM). Tal pesquisa nos propicia descentralizar um pouco a temática dessa pesquisa que, geralmente, são realizadas em regiões mais centrais do Brasil e perceber como as mulheres do Norte vem se organizando e pensando tais problemáticas.

Dessa maneira, a autora identificou que embora as discussões nos grupos analisados sejam de cunho político em torno da mulher, não discutem a questão de gênero como central para o afastamento da presidenta, havendo um silenciamento em relação a esse tema. Esses grupos e regiões foram escolhidos pela autora tendo em vista que ainda são regiões que não se beneficiam de um potencial técnico que a internet oportuniza, propiciando ferramentas para o exercício da cidadania e do ativismo político.

As questões sobre ciberfeminismo são discutidas a partir de outras pesquisas no Brasil que definem esse movimento, mas a autora, diferentemente das pesquisas anteriores, não traça uma linearidade histórica sobre as raízes do movimento. Discute mais sobre como os meios de comunicação, em especial a internet, podem propiciar novas formas de ativismo e de engajamento político, assim como as demais analisadas até o momento na área da comunicação.

$\mathrm{Na}$ área da comunicação o trabalho que tem por metodologia mais diferenciada dos escolhidos é o de Tainan Pauli Tomazetti, intitulado "Movimentos sociais em rede e a construção de identidades: a marcha das vadias -SM e a experiência do feminismo em redes de comunicação", de 2015, que tem por principal eixo de pesquisa uma revisão etnográfica sobre os movimentos sociais e suas lógicas de comunicação em rede para a construção das 


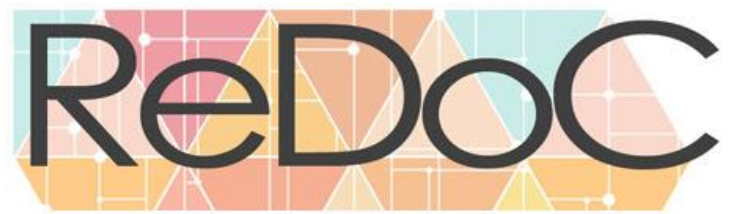

\section{Revista Docência e Cibercultura}

identidades coletivas. Para isso, realiza-se um estudo de caso sobre Marcha das Vadias que aconteceram na cidade de Santa Maria-RS.

Assim, autora percebe a internet como um novo meio de ação política, tendo em vista o mundo atordoado em que estamos inseridos. As Novas Tecnologias da Informação (TIC's), para a autora, vem transformando o agir em sociedade. Dessa maneira, ela busca perceber o quanto é importante essa reflexão em torno dessas novas formas de experimentação política que as possibilidades de articulação em redes fornecem.

O conceito de rede é um eixo central em sua análise, onde há um embasamento de Manuel Castells. As redes, segundo Castells (2013), constituem à nossa maneira de se organizar em sociedade e compõem as formas de interação política, econômica e social. Dessa forma, a autora aponta para a necessidade de se perceber a aproximação dos movimentos sociais a essas redes técnicas; ou seja, a comunicação por meio da internet nos proporciona a reflexão sobre seus usos sociais para fins democráticos e de empoderamento dos sujeitos.

Em relação a pesquisas encontradas na área das Ciências Sociais e Política o trabalho de Michele Cristina de Assis Dutra, de título "Um útero todo seu: público e privado nos posts sobre aborto das blogueiras feministas", de 2014, tem como proposta central analisar nas postagens de mulheres blogueiras como se dá a relação entre público e privado em relação ao aborto. Nesse sentido, a autora diferentemente dos trabalhos da área da comunicação que buscam compreender muito mais de que maneira a informação circula na rede, há uma preocupação em compreender muito mais o discurso e as diferentes perspectivas feministas, o que dá ao trabalho um olhar muito mais sociológico e político.

A pesquisa de Fernanda Rocha intitulado "A quarta onda do movimento feminista: o fenômeno do ativismo digital”, publicado em 2017, realiza também, uma análise mais social e qualitativa sobre o ativismo feminista nas redes sociais. Logo no início da apresentação de seu trabalho, a autora pressupõe que as manifestações feministas de 2015 inauguraram a quarta onda do movimento feminista ou "feminismo 2.0", como ela chama, caracterizada, assim, pela utilização da internet como principal veículo de disseminação de suas pautas. 
A partir de uma metodologia de estudo de caso e coleta de dados, a autora realiza uma análise sobre o conteúdo produzido dentro do blog Escreva Lola Escreva ${ }^{6}$, ativo até os dias de hoje, sendo um dos maiores e mais acessados blogs feministas do Brasil. Em 2015 a popularidade do blog foi tamanha que, após a criadora do mesmo enfrentar críticas misóginas sobre seu material, teve seu site denunciado e, por consequência, suspenso. A repercussão do blog e dessa situação foi tamanha que em 2018 foi sancionada a Lei 13.642/2018, "Lei Lola", que pune qualquer crime praticado na rede mundial de computadores que difundam conteúdos misógino, porém nenhuma infração que se configure como "crime de internet" recebeu alguma penalidade pautada nessa lei.

Sendo um dos únicos trabalhos dentro de um programa específico em estudos de gênero, a dissertação de Leidiane Alves de Farias, intitulado "Ciberfeminismo no Brasil: Um estudo de caso da Rede Universidade Livre Feminista", de 2015, a autora percebe o ciberfeminismo como uma nova prática política que busca traçar um novo olhar para a maneira que mulheres e tecnologia se relacionam tanto dentro do ciberespaço, quanto fora dele. A partir de suas próprias vivência dentro do movimento estudantil e relacionando as teorias de gênero, a autora pretende a partir do estudo de caso, da Universidade Livre Feminista, compreender como as ciberfeministas brasileiras utilizam as Novas Tecnologias da Informação.

A autora entende o ciberfeminismo como

(...) um fenômeno híbrido de intervenções individuais e coletivas, que nasce da relação entre feminismos e tecnologias digitais, estabelecendo um novo quadro de referências pela sua própria existência no contexto político e científico, principalmente na literatura feminista. (FARIAS, 2015, p. 23)

Traçando alguns marcos históricos para o surgimento do movimento, ela alega que essas práticas se proliferaram como um vírus cibernético, chegando ao Brasil onde as mulheres tem cada vez mais acesso a esses espaços, aspecto apontado pela a autora a partir de alguns dados produzidos no ano de 2014. A partir de seu estudo, a autora aponta para a relevância de se discutir a participação e apropriação das mulheres nesses espaços, inclusive levando em

\footnotetext{
${ }^{6}$ Disponível em: <http://escrevalolaescreva.blogspot.com/>
} 


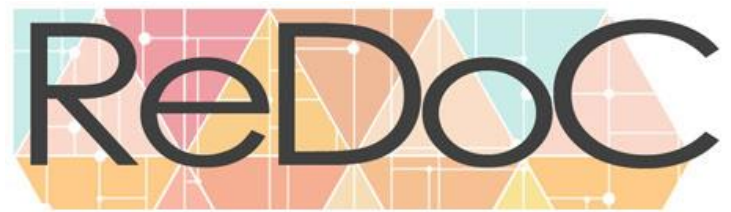

\section{Revista Docência e Cibercultura}

consideração os recortes de raça e classe, aspectos que pouquíssimos trabalhos até então analisados neste texto, levaram em consideração.

$\mathrm{Na}$ área de linguagens a dissertação de Paolla dos Santos intitulada "Arteativismo: expressões do ciberfeminismo comtemporâneo", defendida em 2015, retrata como a arte pode caracterizar o ciberfeminismo. Entre as diversas formas, a autor propõe analisar o projeto artístico Andro Hertz (2014), produzido pela artista Helga Stein com práticas de discurso produzidas dentro de um grupo na rede social facebook. A ênfase da pesquisa está centrada em compreender como os sujeitos se constituem pela e a partir da tecnologia.

Busca-se nesse trabalho pensar no papel que a tecnologia assume na vida das pessoas, possibilitando reconstruir novas subjetividades e identidades aos sujeitos sem a possibilidade de desassociar o papel que a tecnologia vem exercendo sobre os corpos humanos. Importantíssimo salientar que a autora faz algumas distinções entre o ciberfeminismo desenvolvido na Austrália e na Europa com o brasileiro latino-americano, tendo em vista que esses possuem características próprias, como já mencionados em trabalhos anteriores.

As formas de socialização promovidas pela cibercultura construíram e constroem debates importantes em torno das relações de gênero, mulheres e poder. Paulatinamente, a autora percebe que estamos migrando a maneira de se viver em sociedade para o espaço virtual, trazendo nossos conflitos, desejos, anseios e embates para dentro desse outro espaço, onde a vida real já não pode mais ser desvinculada da virtual.

O único trabalho realizado na área de educação foi a tese de doutorado de Lucélia de Moraes Braga Bassalo, intitulada "Entre sentidos e significados: um estudo sobre visões de mundo e discussões de gênero de jovens internautas", de 2012, que busca compreender de que maneira a juventude se articula em meio as redes sociais, tendo em vista que esta categoria é talvez a principal protagonista do meio. A autora justifica seu estudo partindo da premissa de que é preciso desenvolver estudos em torno das juventudes, pois, desta maneira, é possível ampliar as políticas educacionais do país que dialoguem melhor com tal grupo geracional. Para ela, “(...) a juventude tem um papel importante nas sociedades, tanto como 
continuidade, quanto como agente de mudança, de revitalização do status quo. ". (BASSALO, 2012, p.17)

Além disso, a autora ressalta que os estudos sobre juventudes, não levam em conta a diversidade juvenil e suas problemáticas. Dessa maneira, aponta para uma escassez de pesquisas que se propõem a discutir gênero e juventude, levando em consideração dentro desse recorte, o fracasso e permanência escolares, por exemplo.

A constante inserção de novas tecnologias na sociedade causa profundas mudanças e a juventude se apresenta como grupo que mais tem facilidade em se adaptar às novas realidades. Para além do vocabulário, a internet promove uma forte interação social de maneira desterritorializadas, mas conectadas em rede, ressignificando assim as noções de sociabilidade.

A autora levanta o seguinte questionamento: "Se a internet é um espaço de experiência de interação social que conta com a participação intensiva de jovens, quais espaços virtuais são propostos e mantidos por eles?" (BASSALO, 2012, p 23). Além disso, discorre-se em cima da ideia de que “(...) os diferentes espaços de convivência na internet podem ser considerados como produtos culturais da contemporaneidade, pois representam as experiências dos sujeitos, suas intenções, opiniões, argumentos e disposições sociais. ”. (BASSALO, 2012, p. 24). Dessa forma, o principal objetivo de sua pesquisa é identificar quais são as orientações coletivas de jovens feministas, seus posicionamentos, interpretações e como elas expressam isso por meio das imagens presentes no blog dialogoj (Diálogo Jovem uma Agência de Notícia Jovem Feminista) durante o período de 2007 a 2011.

Assim como as pesquisas anteriores, a autora também cita Donna Haraway como um marco no início do ciberfeminismo, embora a própria autora não a utilize com esse mesmo sentido. Para Haraway todos nós somos ciborgues, sendo o ciborgue, uma criatura pósgênero, ou seja, não há uma oposição entre natureza e cultura pois ela está diluída na tecnologia. A partir dessa premissa a autora propõe a desnaturalização do ser mulher como uma concepção natural e por não termos nenhuma essência que seja capaz de nos sustentar de fato, todas as formas de opressão de gênero podem ser desconstruídas, visto que se o ciborgue 


\section{Revista Docência e Cibercultura}

é algo construído, tudo aquilo que é construído em torno da hierarquização e dominação pode ser destruído.

Pensando em um novo feminismo, Haraway propõe que se aceite a tecnologia, entendendo-a como uma extensão do corpo, da vida e da intimidade. Assim, a mesma diz que esse "novo" feminismo se busca descontruir preconceitos e evitar erros cometidos pelos feminismos anteriores, como os de racismo e de lesbofobia, por exemplo, possibilitando criar uma solidariedade no âmbito da diferença.

Apesar de o enfoque deste estado da arte não ser a análise de artigos, até o presente ano de 2020 não se encontrou nenhuma dissertação ou tese que tivesse como discussão o movimento \#EleNão, que foi demonstrado como um exemplo recente do ativismo de mulheres nas redes sociais.

Sendo assim, o artigo de Maíra de Sousa e Brenda Rachit, que tem por título "Mobilizações pré-eleições presidenciais 2018 no Pará: grupos e eventos relacionados à \#EleNão no Facebook", publicado em 2019, traz importantes contribuições sobre a organização do movimento no país como um todo. Assim como a maioria dos trabalhos encontrados sobre o tema, este também faz parte da área da comunicação, porém, mesmo sendo um trabalho curto, nos fornece discussões bem atuais e fundamentadas na teoria do sociólogo Manuel Castells (2013), abordando os conceitos de sociedade em rede e site de redes sociais.

A partir da observação tanto dos grupos criados no facebook de carácter nacional, quanto especificamente do Pará, as autoras identificaram que a participação nesses ambientes

Possibilitaram o engajamento de mulheres que não tinham envolvimento ativo político, mas que, a partir das trocas proporcionadas pelo encontro de mulheres com indignações comuns, puderam exercitar sua cidadania nos sites de redes sociais e ainda mais expressivamente no espaço urbano. As conexões entre essas mulheres estabeleceram laços sociais e ajudaram na construção de capital social, de popularidade e legitimidade do movimento contra Jair Bolsonaro. (SOUSA e RACHIT, 2019, p.87)

Este artigo nos possibilita vislumbrar e até mesmo tecer comparações entre os trabalhos anteriores produzidos, visto que a maioria foram produzidos antes de 2018. Percebemos, 


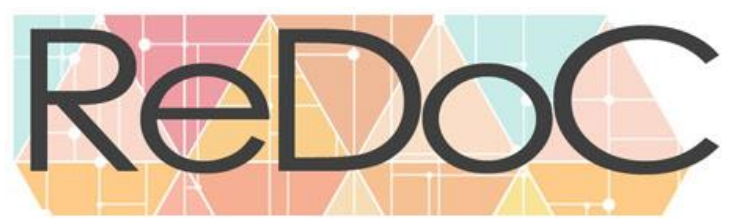

\section{Revista Docência e Cibercultura}

também, o quanto o ativismo feminista vem crescendo nas redes sociais e ao contrário do que o senso comum acredita, ele se consolida nos espaços físicos como nas ruas, nos lares, nas escolas; enfim em espaços que possuem interação social. Tem força até mesmo para gerar aprovação de leis, como é o caso por exemplo, da "Lei das Doulas" no Rio de Janeiro, estudado pela já mencionada Joice Adriana Enzeler em 2017.

Traçando ainda algumas semelhanças entre as pesquisas analisadas, percebemos que há um consenso sobre a atuação dos movimentos sociais por meio das redes ser muito mais positiva do que negativa, pois reafirma a velocidade com que a informação circula nesse ambiente. Essa posição rompe com uma concepção saudosista geralmente marcada pelos dizeres "no meu tempo que as coisas eram realmente boas!", "no meu tempo é que as coisas realmente funcionavam". Percebemos que emerge na atualidade uma geração comprometida e que busca desconstruir discursos ainda muito naturalizados. Essa geração se mescla com a geração ligada aos movimentos sociais nas décadas de 1980 e 1990 e busca uma forma mais eficaz para diminuir as desigualdades nas mais diversas esferas sociais, percebendo o meio virtual como uma importante ferramenta de atuação.

Sendo assim, esses movimentos precisam serem analisados e discutidos, pois, como diversos trabalhos mostraram, já é difícil na atualidade distinguirmos o real do virtual, visto que ambos acontecem simultaneamente e são capazes de determinar as identidades dos sujeitos.

Ademais, todos os trabalhos escolhidos e encontrados para análise foram produzidos e muitos orientados por pesquisadoras mulheres, demonstrando o protagonismo das mulheres na pesquisa e discussão de si para outras mulheres. Se não dermos voz nós mesmas, quem nos dará? Somos nós mulheres que precisamos escrever sobre o nosso protagonismo na história.

\section{PARA NÃO CONCLUIR!}

A recente onda do pensamento conservador que se abateu pelo país nos últimos anos afeta, principalmente, as minorias populacionais, sendo as mulheres um dos alvos de ataques 
do conservadorismo, reafirmando sua vulnerabilidade diante as mais diversas formas de violência.

Nesse sentido, percebemos que os direitos das mulheres nunca estão completamente seguros, eles precisam ser constantemente reafirmados. Por isso é tão importante que cada vez mais mulheres tenham acesso à informação para que saibam o quão importante, e necessário, é a reafirmação dos seus direitos, para não perdermos aquilo que já foi conquistado. $\mathrm{O}$ ativismo feminista que acontece por meio das redes sociais pode contribuir para esse acesso à informação, pois fornece conteúdos de linguagem acessível e de alcance fácil.

De acordo com Brandão (2017), a educação pode ser compreendida nas mais diversas formas, não apenas em espaços institucionalizados de ensino, mas sim em quaisquer espaços que houverem “(...) redes e estruturas sociais de transferência de saber”. (BRANDÃO, 2017, p.6). Assim, o ciberespaço não se resume apenas ao entretenimento e ao consumo, mas, sim, como um espaço de engajamento político-social e potente na propagação do conhecimento.

Logo se faz necessário discutir sobre o protagonismo das mulheres nos movimentos sociais, reconhecendo a sua atuação e não as tratando como simples coadjuvantes, como a história vem fazendo a tantas gerações. É necessário demonstrar as maneiras de articulação do movimento feminista atual em prol da diminuição das desigualdades e o movimento de resistência diante dos retrocessos aos quais os direitos das mulheres e das minorias têm sido vítimas.

Dessa forma, torna-se de extrema importância o desenvolvimento de pesquisas que busquem abordar a presença de mulheres nas esferas sociais, não como um aspecto "exótico", mas enquanto sujeitos ativos da transformação social. Além disso, compreender, sobretudo, que a educação se faz não apenas nos espaços institucionalizados de ensino, mas também nas nossas ações do cotidiano, em que mesmo uma simples interação dentro de uma rede social pode vir a contribuir na nossa construção enquanto sujeitos.

Fechamos esse texto sabendo que a luta pelos direitos das mulheres é uma luta árdua e que deve ser travada cotidianamente, como destaca Simone de Beauvoir na epigrafe desse 


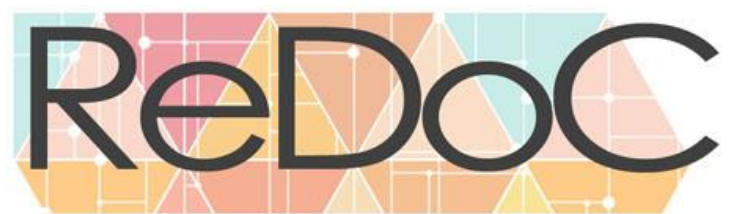

\section{Revista Docência e Cibercultura}

texto. Compreendemos que a pesquisa também compõe a luta das mulheres e que o Brasil vem contribuindo também nessa frente de luta com pesquisas que respondam sobre feminismo nas redes sociais.

\section{REFERÊNCIAS}

ALCÂNTARA, Lívia Moreira de. Ciberativismo e movimentos sociais: mapeando discussões. Aurora: revista de arte, mídia e política, São Paulo, v.8, n.23, p. 73-97, jun.set.2015. Disponível em: <http://ken.pucsp.br/aurora/article/view/22474/18888>. Acesso em: 18 de fevereiro de 2019.

BASSALO, Lucélia de Moraes Braga. Entre sentidos e significados: um estudo sobre visões de mundo e discussões de gênero de jovens internautas. Tese (Doutorado em Educação) Faculdade de Educação, Programa de Pós-graduação em Educação, Universidade Federal de Brasília. Brasília: 2012.

BEAUVOIR, Simone de. O Segundo Sexo. Nova fronteira. São Paulo, 2009.

BOGADO, Maria. Rua. In: HOLLANDA, Heloisa Buarque de. Explosão Feminista. São Paulo: Companhia das Letras, 2018.

BRANDÃO, Carlos Rodrigues. O que é educação. Brasiliense: São Paulo, 2017. (Versão Digital)

CASTELLS, M. Redes de indignação e esperança: movimentos sociais na era da internet. Rio de Janeiro: Zahar, 2013.

DE FARIAS, Leidiane Alves. Comunicação e Feminismo: experiências ciberfeministas no Brasil. Dissertação (Mestrado) - Faculdade de Filosofia e Ciências Humanas, Programa de Pós-Graduação em Estudos Interdisciplinares sobre Mulheres Gênero e Feminismo. Salvador: 2015.

ENZLER, Joice Adriana. Ciberfeminismo e Saúde: uma análise do caso da aprovação e implementação da Lei das Doulas (7314/2016) no estado do Rio de Janeiro. Dissertação (Mestrado) - Mestrado em Informação e Comunicação em Saúde, Fundação Oswaldo Cruz (FIOCRUZ). Rio de Janeiro: 2017

HIRATA, Helena et al. (ORG.). Dicionário Crítico do Feminismo. Fundação Editora UNESP (FEU). São Paulo: 2009.

LEMOS, Marina Gazire. Ciberfeminismo: novos discursos do feminino em redes eletrônicas. Dissertação (Mestrado) - Mestrado em Comunicação e Semiótica, Pontifícia Universidade Católica de São Paulo. São Paulo: 2009. 


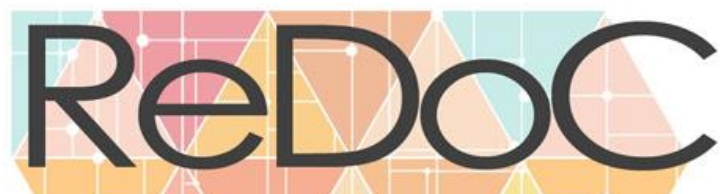

\section{Revista Docência e Cibercultura}

LÉVY, Pierre. Cibercultura. Editora 34: São Paulo, 2010.

MAIGRET, E. Sociologia da Comunicação e das Mídias. São Paulo: Senac, 2010.

REIS, Carolina. O novo feminismo. Disponível em https://expresso.pt/sociedade/2016-09-25O-novo-feminismo acessado em maio de 2019.

SCHLINDWEIN, Ana Flora. Dos periódicos oitocentistas ao ciberfeminismo: a circulação das reivindicações feministas no Brasil. Dissertação (Mestrado) - Mestrado em Divulgação Científica e Cultural, Universidade Estadual de Campinas. Campinas: 2012.

SOUSA, Maíra; RACHIT, Breda. Mobilizações pré-eleições presidenciais 2018 no Pará: grupos e eventos relacionados à \#EleNão no facebook. In: Aturá Revista Pan-Amazônica de Comunicação, Palmas, v. 3, n. 1, p. 66-86, jan-abr. 2019.

Este é um artigo de acesso aberto distribuído sob os termos da Licença CreativeCommons Atribuição Não Comercial-Compartilha Igual (CC BYNC- 4.0), que permite uso, distribuição e reprodução para fins não comerciais, com a citação dos autores e da fonte original e sob a mesma licença. 